\title{
Nodular Amyloid Goiter: An Extremely Rare and Unusual Presentation of Amyloidosis
}

\author{
Karuna Gupta ${ }^{1}$, Maryem Ansari2², Kalpana Mangal'2, Jayanti Mehta ${ }^{1}$, Kusum Mathur ${ }^{1}$ \\ 1Professor, ${ }^{2}$ Assistant Professor, \\ Department of Pathology, SMS Medical College, Jaipur, Rajasthan, India.
}

\begin{abstract}
Amyloidosis is a condition in which there is deposition of misfolded proteins at extracellular sites. This may be generalized or localized. In generalized or systemic form, many organs are involved, commonest being the kidney, liver, spleen, heart etc. Involvement of the thyroid is a rare phenomenon. Even if it is involved, it is not one of the organs to be involved early in the stage of disease. The localized form of amyloidosis is a result of amyloid protein deposits in specific areas of the body and is distinct from systemic form. The manifestations are subtle and confined to particular organ. We report a case in which the patient presented with enlargement of the thyroid and was finally diagnosed to have amyloid deposits in thyroid. This case is unique as amyloidosis involving the thyroid primarily and that too leading to its enlargement is a rare phenomenon.
\end{abstract}

\section{INTRODUCTION}

Amyloidosis is a rare disease that occurs as a consequence of abnormal protein deposits in body tissues and organs. Depending on the structure of the particular amyloid, the protein can accumulate in an isolated tissue or be widespread, affecting numerous organs and tissues. Amyloidosis has been classified into three major types- systemic or generalised amyloidosis, localised and heredofamilial amyloidosis. Systemic amyloidosis subsumes the important subtypes, primary and secondary amyloidosis. In primary amyloidosis the disorder lies within the immunoregulatory cells. Secondary amyloidosis occurs as a result of another illness, including chronic infections, chronic inflammatory diseases. Heredofamilial amyloidosis is the familial form of amyloidosis. There are several proteins which can get deposited and may result in various forms of localized amyloidosis. In either of these types, thyroid gland may be involved though this is very rare.

\section{CASE REPORT}

We report a case of 46 year old male who presented with swelling on the anterior side of neck along with difficulty in swallowing and shortness of breath. A detailed clinical examination along with routine investigations was done. On clinical examination the thyroid was palpable. It was firm in consistency, nodular and moved with deglutition. Thyroid profile done revealed a euthyroid state initially, but later on showed transient rise in TSH favoring a hypothyroid state. Anti-thyroid peroxidase and anti thyroglobin were raised. Fine needle aspiration cytology was done and showed features of autoimmune thyroiditis along with
Keywords: Amyloid goiter, Congo red, Polarizing microscopy.

${ }^{*}$ Correspondence to:

\section{Dr Maryem Ansari,}

Flat no 301, Golden Oak apartments -2, Devi Marg, Bani Park, Jaipur, Rajasthan, India.

Article History:

Received: 27-10-2016, Revised: 22-11-2016, Accepted: 29-11-2016

\begin{tabular}{|l|c|}
\hline \multicolumn{2}{|c|}{ Access this article online } \\
\hline Website: & \\
www.jjmrp.com & \\
\hline DOI: & \\
10.21276/jmrp.2016.2.6.032 & \\
\hline
\end{tabular}

granulomatous change. Ultrasonography showed multiple nodules of varying size with peripheral vascularity suggestive of adenomatoid goiter.

The patient was a known hypertensive and was on regular antihypertensives. Investigations revealed raised urea and creatinine levels. Serum electrolytes were normal. Urine showed the presence of proteins. On imaging however the kidney size was normal and showed no changes. The patient was not placed on dialysis but was treated medically for acute kidney injury.

Two years back the patient was diagnosed as having pulmonary tuberculosis. He had taken a full course of anti-tubercular drugs. Apart from this the patient also had pain and stiffness in multiple joints. RA factor was done but it came out to be negative. With this work-up a provisional diagnosis of nodular goiter along with autoimmune thyroiditis was made.

Surgical excision by hemithyroidectomy was planned to relieve the pressure symptoms and provide cosmetic correction. The surgery was uneventful and the excised specimen was sent to the pathology section for further study. Gross study of the specimen revealed encapsulated mass with a nodular external surface. Cut surface smooth, pale, waxy and vaguely nodular. (Fig. 1) Histopathological examination revealed eosinophilic amorphous material around normal follicles with interspersed adipocytes. (Fig. 2) At places many giant cells with lymphocytic infiltration were seen. Congo red stain showed pinkish-red staining of the deposits. (Fig. 3) When viewed under the polarizing light, apple green birefringence was seen, confirming the deposits to be of amyloid. (Fig. 4) 


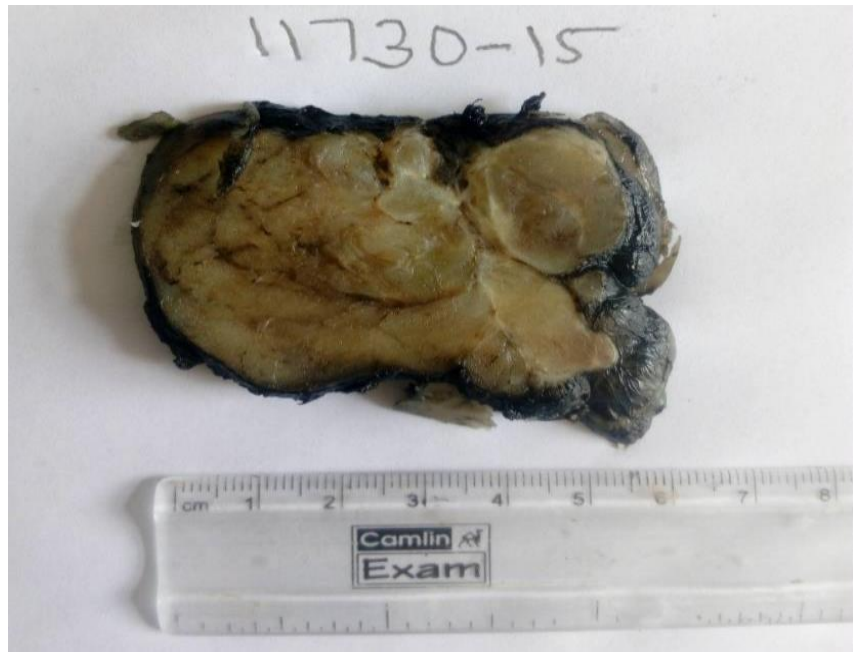

Fig 1: Gross appearance of resected hemithyroidectomy specimen. Cut surface is pale waxy and vaguely nodular

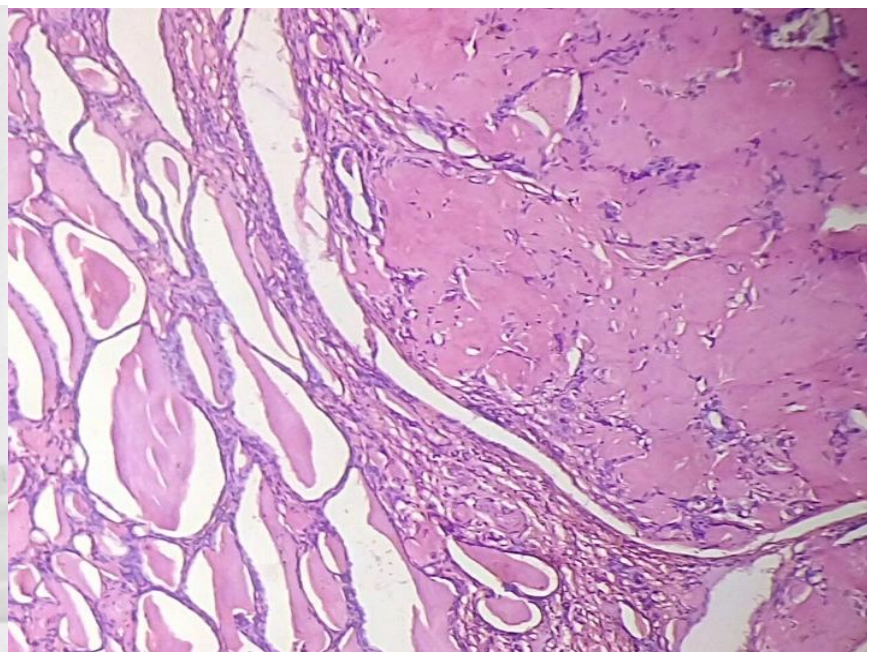

Fig 2: (40X) H\&E. Deposits of eosinophilic material compressing some follicles whereas remaining appear to be dilated. Normal thyroid tissue can be seen in left side.

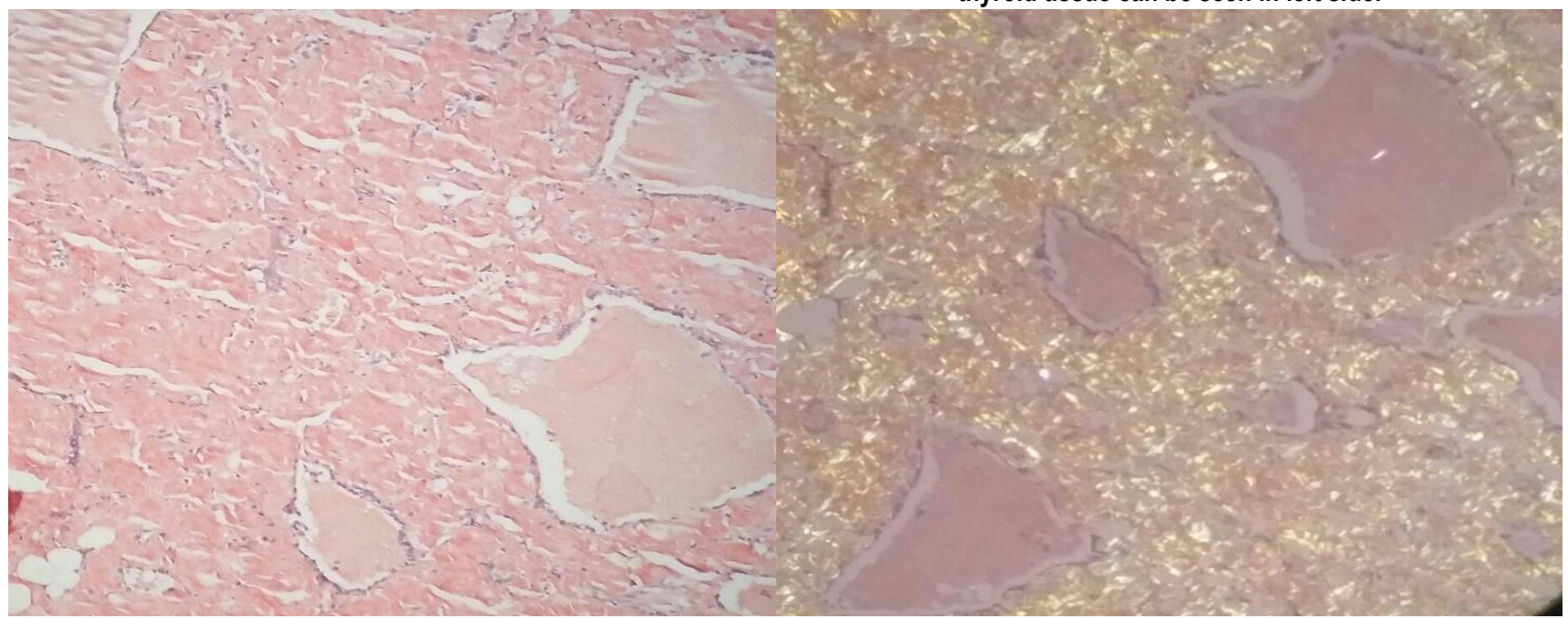

Fig 3: (40X) Congo red staining pinkish red deposits of amyloid. Few colloid filled follicles are seen

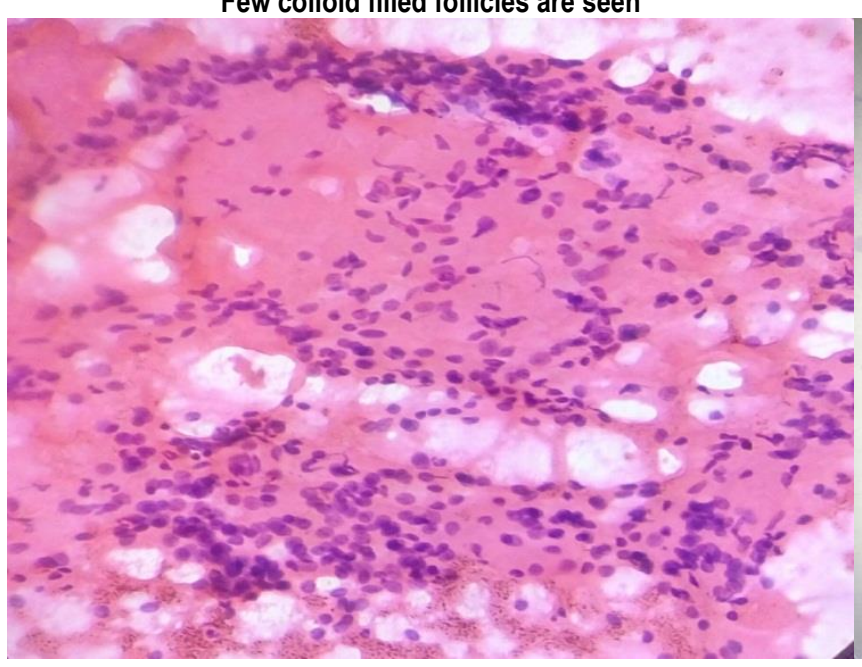

Fig 5: Cytosmear H\&E (40X). Eosinophilic areas depicting amyloid along with follicular cells and lymphocytic infiltration.

\section{DISCUSSION}

Amyloidosis is known to involve various organs. Involvement of the thyroid is not very common and enlargement of the thyroid due to amyloidosis is even rarer. The first case of thyroid involvement in systemic amyloidosis was reported in 1855. ${ }^{1}$ Enlargement of the
Fig 4: (40X) Congo Red staining on polarising microscopy showing apple green birefringence.

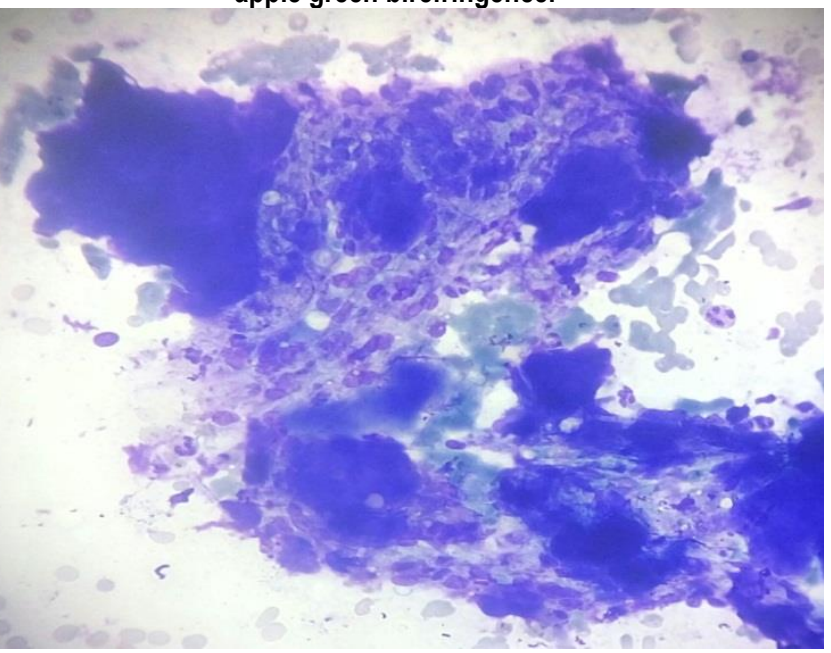

Fig 6: Cytosmear MGG (40X) showing dense amyloid deposits along with lymphocytic infiltration of the follicular cells

thyroid due to amyloidosis was reported by James in $1858 .{ }^{2}$ Elseberg coined the term "amyloid goiter" in 1904.

Small amount of amyloid deposits do not cause any symptoms and hence go undetected. 30 to $80 \%$ of the subjects may have thyroid involvement not leading to any clinical symptoms. ${ }^{3}$ Much of 
the study has therefore been done on the autopsy findings. Apart from systemic amyloidosis, amyloid has been reported in thyroid in patients of medullary carcinoma, micro-follicular carcinoma thyroid and Reidels thyroiditis. ${ }^{4-6}$

The age of presentation varies. In a large review study comprising of thirty patients median age was reported to be 43.7 years with the age range of 23 to 75 years. This condition affected males mostly. ${ }^{7}$ Most of the patients present with features related to symptoms of other organ involvement. Presentation primarily in the thyroid is rare. There are only a few case reports where amyloidosis presented first in the thyroid. ${ }^{8}$

When thyroid is involved there is bilateral enlargement of both the lobes as compared to the unilateral involvement in cases of malignancy. In our patient there was involvement of both the lobes but the right lobe was more enlarged. Hence only right sided hemithyroidectomy was performed. This patient had pressure symptoms like difficulty in swallowing and difficulty in breathing. Similar symptoms have been reported in many other patients of amyloid goiter. ${ }^{7}$ Surgery was planned in our patient to provide relief from those symptoms.

Thyroid profile done in our patient revealed a normal thyroid function test initially followed by a transient period of hypothyroidism, which was corrected medically by thyroxine supplementation. Evaluation of the patients for thyroid profile shows normal thyroid function tests even if hypothyroid and hyperthyroid states are detected in a minority of the cases. ${ }^{7}$ Fine needle aspiration may be helpful and may indicate the presence of amyloid in thyroid. ${ }^{9} \mathrm{FNA}$ is a safe and quick diagnostic aid though the reliability of detecting amyloid in thyroid is less as compared to histopathology. In many cases FNA was not able to render the diagnosis of amyloid goiter. ${ }^{10}$ In this case also FNAC showed features of lymphocytic thyroiditis initially. The areas of amyloid were interpreted as colloid. On reviewing the slides the presence of amyloid was appreciated. (Fig. $5 \& 6$ )

Imaging studies may also indicate towards the presence of amyloid deposits. Hyperechoic thyroid parenchyma with a few areas of reticular pattern may be noted on ultrasound examination in the disease. Some authors have reported that ultrasonography reveals complex or hypoechoic mass when amyloid deposits predominate and in case where fatty infiltrate is abundant, increased echogenicity is seen. ${ }^{11} \mathrm{CT}$ and MRI also give variable intensities depending on the relative amount of fat and amyloid. Thus, these imaging modalities may point towards the diagnosis of amyloid goiter.

Histopathological examination remains the gold standard for diagnosis. It usually reveals extensive infiltration of parenchyma by eosinophilic amorphous material. Fat cell metaplasia has been reported in many cases. Congo red, thioflavin, methyl violet stains may also be helpful. Congo red viewed under polarizing light is confirmatory as it gives apple green birefringence. Thioflavin $T$ viewed under immunofluorescent microscope gives yellow green birefringence but the specificity is low as many other structures are fluorescent. This stain has also been tried by many authors for diagnosing amyloidosis in thyroid. ${ }^{9}$ As there was suspicion of amyloidosis in our patient on histopathology, we performed Congo red staining on the sections and viewed it under polarizing light. There was an apple green birefringence. So a diagnosis of amyloidosis was confirmed. Further sections were given from the excised thyroid specimen so as to examine extensively for any differentiated carcinomas which may arise in an amyloid goiter. ${ }^{[12]}$ But no such malignancy was noted in this patient.

The patient was advised investigations to rule out systemic amyloidosis. The patient did not give consent so many of the tests could not be carried out.

\section{CONCLUSION}

Enlargement of thyroid may be a manifestation of underlying amyloidosis and may mimic goiter, so proper investigations should be done with special emphasis on histopathology and special stains, as this may be missed on cytological examination and imaging studies. A thorough histopathological examination by exhaustive gross sectioning is must to rule out a malignant lesion associated with amyloid. Systemic involvement should also be investigated for, as primary amyloidosis involving only the thyroid is rare. On confirmation of diagnosis proper treatment should be planned.

\section{REFERENCES}

1. Arean VM, Klein RE. Amyloid goiter: Review of the literature and report of a case. Am J Clin Pathol. 1961;36:341-55.

2. James PD. Amyloid goiter. J Clin Pathol 1972; 25: 683-8.

3. Briggs MGW. Amyloidosis. Ann Intern Med. 1961;55:943-957.

4. Livosi VA. Medullary carcinoma. In: Bennington JL ed. Surgical pathology of the thyroid. WB Saunders: Philadelphia; 1990. p. 213-52. 5. Valenta LJ, Michel-Bechet M, Mattson JC, Singer FR. Microfollicular thyroid carcinoma with amyloid rich stroma, resembling the medullary carcinoma of the thyroid (MCT).Cancer. 1977 Apr; 39(4):1573-86.

6. Melato M, Mlac M. Riedel's thyroiditis and isolated thyroid amyloidosis. Pathologica. 1978 Jan-Feb;70(999-1000):33-7.

7 Villa F, Dionigi G, Tanda ML, Rovera F, Boni L. Amyloid Goiter. International Journal of Surgery, 2008; 6:16-18.

8. Oueslati I, Khiari $\mathrm{K}$, Kaaroud $\mathrm{H}$ et al. Amyloid goitre as the first manifestation of systemic amyloidosis. Tunis Med. 2016 Jan; 94(1):82

9. Solanki VV, Vaghela DU, Marekar AK, Chauhan SR, Baxi SN. A Rare Case of Amyloid Goiter: Ultrasonographic Findings and Thioflavin T Staining. Adv Hum Biol. 2014;4(3):60-63.

10. Khullar R, Sharma A, Goel A, Bagchi N, Soni V, Baijal M, Chowbey PK. Amyloid goitre: A rare case report. Indian J Surg 2006;68:104-5.

11. Aksu AO, Mustafa N. Diffuse fatty infiltration of the thyroid gland in amyloidosis. J Ultrasound Med 2010; 29:1251-1255.

12. Coca-Pelaz A, Vivanco-Allende B, Alvarez-Marcos C, SuarezNieto $C$. Multifocal papillary thyroid carcinoma associated with primary amyloid goiter. Auris Nasus Larynx. 2012 Oct;39(5):549-51.

\section{Source of Support: Nil. Conflict of Interest: None Declared.}

Copyright: (c) the author(s) and publisher. IJMRP is an official publication of Ibn Sina Academy of Medieval Medicine \& Sciences, registered in 2001 under Indian Trusts Act, 1882.

This is an open access article distributed under the terms of the Creative Commons Attribution Non-commercial License, which permits unrestricted non-commercial use, distribution, and reproduction in any medium, provided the original work is properly cited.

Cite this article as: Karuna Gupta, Maryem Ansari, Kalpana Mangal, Jayanti Mehta, Kusum Mathur. Nodular Amyloid Goiter: An Extremely Rare and Unusual Presentation of Amyloidosis. Int J Med Res Prof. 2016; 2(6):158-60. DOI: 10.21276/ijmrp.2016.2.6.032 